\title{
95. Effects of Placement of Lesions in Amygdaloid Areas upon Ovarian Function in PMS-Primed Immature Rats
}

\author{
By Takeo MACHIDA*) \\ Zoological Institute, Faculty of Science, University of Tokyo \\ (Comm. by Yô K. OKadA, M. J. A., June 2, 1972)
}

Considerable efforts have been directed towards the elucidation of the mechanism involved in the incidence of ovulation in immature rats after a single injection of pregnant mare's serum gonadotropin (PMS). The results of carefully-timed hypophysectomy, of placement of lesions in the hypothalamus and of injections of adrenergic or cholinergic blocking agents have strongly suggested the involvement of a neuroendocrine mechanism in the phenomenon. ${ }^{1)-4)}$ Furthermore, Quinn and Zarrow ${ }^{5)}$ reported that the medial preoptic area and the basal region of the anterior hypothalamus might be the structures concerned.

On the other hand, several investigators have indicated the participation of extrahypothalamic areas, the amygdala, in particular, in the regulation of the function of the hypothalamo-hypophyseal gonadal system..$^{6)-9)}$ Machida and Takewaki ${ }^{10)}$ recently reported that placement of electrolytic lesions in the region dorsolateral to the paraventricular nuclei in immature rats with gonadotropin-induced corpora lutea in their ovaries elicited the formation of deciduomata following uterine traumatization, suggesting that the region was concerned with the control of the release of prolactin-inhibiting factor (PIF) and consequently of prolactin in the animals.

In the light of these findings of previous workers, it was thought interesting to study the possible role played by the amygdala in the secretion of gonadotropin and/or prolactin from the anterior hypophysis in PMS-primed immature rats. The present paper deals briefly with the effects of bilateral placement of electrolytic lesions in the amygdaloid area upon the incidence of luteinization of the ovaries and the deciduomal reaction of the uterine endometrium in such animals.

Materials and methods. Immature female rats of the SpragueDawley strain were used in these experiments. All rats were weaned at 21 days of age and thereafter kept on rat chow and water $a d$

*) Present address: Division of Biology, Metropolitan Institute of Gerontology, 35-2 Sakae-cho, Itabashi, Tokyo 173. 
libitum. At 23 days of age, each rat was placed in a stereotaxic instrument under ether anesthesia and bilateral placement of electrolytic lesions was made in the amygdala by means of stainless steel electrodes. The electrodes, $0.35 \mathrm{~mm}$ in diameter and insulated with Epoxylite to within $0.8 \mathrm{~mm}$ of the tip, were placed according to coordinates based on the rat brain atlas of De Groot ${ }^{11)}$ modified for immature rat brain. An anodal direct current of $1.5 \mathrm{~mA}$ was delivered through the electrode for 5-10 seconds, the cathode being placed on the skin incision.

At 26 days of age, i.e., 3 days after placement of lesions, rats were given a single subcutaneous injection of 5 I.U. PMS (Primantron, Schering A. G., Berlin) in $0.1 \mathrm{ml}$ of a $0.9 \% \mathrm{NaCl}$ solution. Since the vaginal orifice was formed 3 days after the injection in these rats, daily vaginal smears were taken from 29 days on until the day of sacrifice. On the 6th day after PMS injection, rats were laparotomized under ether anesthesia and the right uterine horn was traumatized by the method as described by Takewaki. ${ }^{12)}$ Those receiving PMS injection but given neither brain lesions nor uterine trauma served as controls.

Rats were weighed and sacrificed when they reached 36 days of age. Ovaries, adrenals and traumatized and intact uterine horns were dissected out, weighed, fixed in Bouin's solution and processed for histological study. In ovaries of each rat, corpora lutea were counted and their diameters were measured by the procedures similar to those described previously. ${ }^{13)}$ Brains were also fixed in Bouin's solution, cut into serial sections at $10 \mu$ and stained with thionin for checking the lesions.

Results. Localization of brain lesions. In 12 rats, bilateral lesions were successfully placed in the amygdaloid areas. The lesions usually included the nucleus amygdaloideus corticalis (ACO), the nucleus amygdaloideus basalis pars lateralis (ABL), and the nucleus amygdaloideus medialis (AME), while the nucleus amygdaloideus basalis pars medialis, the nucleus amygdaloideus lateralis, and the nucleus amygdaloideus centralis invariably escaped destruction (Fig. 1). As shown in Fig. 1, the lesions were approximately the same in both location and size among the 12 rats.

Ovarian histology and weights of ovaries and adrenals. Following injections of PMS, the 12 rats carrying amygdaloid lesions developed 4-39 (16.3 \pm 3.9$)$ corpora lutea, measuring $0.75-1.25 \mathrm{~mm}$ in diameter, in their ovaries, while the 7 control rats bearing no brain lesions formed 5-10 (7.8 \pm 0.8$)$ corpora lutea of similar size (Table I). The difference in number of corpora lutea between the two groups was not significant statistically $(p>0.05)$. There were also no 


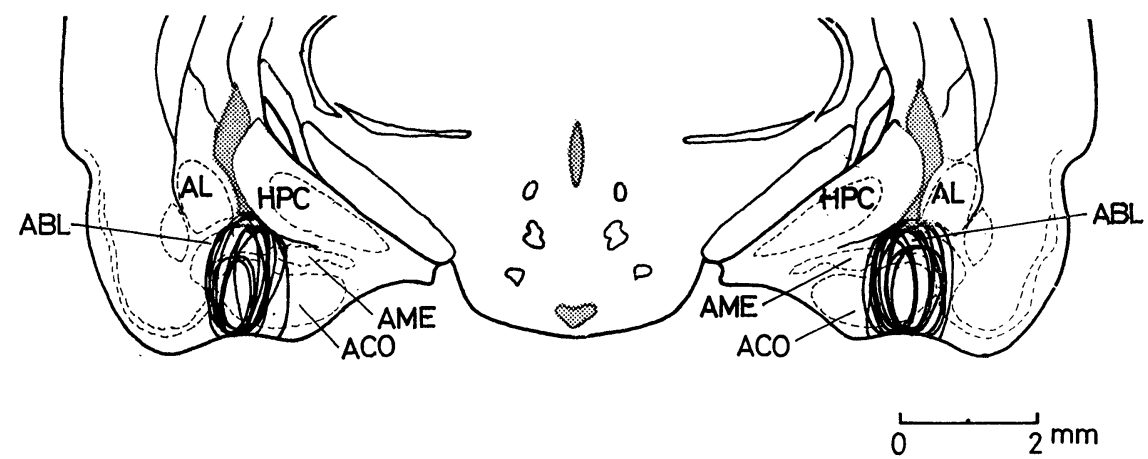

Fig. 1. Localization of amygdaloid lesions in the immature rats primed with PMS. Four of the 12 rats bearing lesions in the amygdala formed a greater number of corpora lutea as compared with the rest of the animals. However, there were no appreciable differences in both location and size of the lesions among the 12 rats.

ABL: Nucleus amygdaloideus basalis pars lateralis, ACO: Nucleus amygdaloideus corticalis, AL: Nucleus amygdaloideus lateralis, AME: Nucleus amygdaloideus medialis, HPC: Hippocampus.

Table I. Effects of amygdaloid lesions upon luteinization of ovaries and uterine response to traumatization in PMS-primed immature rats

\begin{tabular}{lrcccccc}
\hline Group & $\begin{array}{c}\text { No. } \\
\text { of } \\
\text { rats }\end{array}$ & $\begin{array}{c}\text { No. of } \mathrm{CL} \\
\text { per } \\
\text { rat }\end{array}$ & $\begin{array}{c}\text { Body } \\
\text { weight } \\
(\mathrm{g})\end{array}$ & \multicolumn{3}{c}{ Organ weight(mg/100g B.W.) } \\
\cline { 5 - 8 } & & & & & & & \\
ovaries & adrenals & $\begin{array}{c}\text { traumatized } \\
\text { uterine horn uterine horn }\end{array}$ \\
\hline control & 7 & $7.8 \pm 0.8^{1)}$ & $84 \pm 3$ & $36.2 \pm 3.4$ & $22.3 \pm 1.5$ & - & - \\
lesioned & 12 & $16.3 \pm 3.9$ & $85 \pm 2$ & $50.3 \pm 8.9$ & $22.9 \pm 1.3$ & $74.1 \pm 7.2^{*}$ & $39.1 \pm 2.2$ \\
\hline
\end{tabular}

CL: Corpora lutea, 1) mean \pm standard error.

*) Significantly different from the value for the intact horns $(0.001<p$ $<0.01)$.

significant differences in weights of ovaries and adrenals between these groups $(p>0.05)$. However, the ovaries of 4 of the 12 lesioned rats were heavily luteinized, containing 26-39 (33.5 \pm 3.1$)$ corpora lutea, while those of the remaining 8 rats exhibited $4-15(7.7 \pm 1.4)$ corpora lutea. The heavily luteinized ovaries of the 4 rats weighed $90.6 \pm 6.0 \mathrm{mg}$ per $100 \mathrm{~g}$ body weight and the mildly luteinized ones of the other $8,30.1 \pm 2.0 \mathrm{mg}$.

Uterine response to trauma and the state of vaginal smears. In all the rats receiving PMS, the vaginal orifice was formed 3 days after injection, i.e., at 29 days of age, vaginal smears of the estrous type occurring on the next day. From the 5th day after PMS injection on, diestrous vaginal smears continued until the day of sacrifice in all the animals. In the 4 amygdala-lesioned rats with heavily 
luteinized ovaries, vaginal smears frequently contained copious mucus. None of the 12 rats bearing lesions in amygdaloid areas exhibited the positive deciduomal reaction to uterine trauma, although the traumatized uterine horns were significantly greater in weight than the contralateral intact horns $(0.001<\mathrm{p}<0.01)$.

Discussion. Evidence for the involvement of the amygdala in the regulation of the hypothalamo-hypophyseal gonadal function seems to be unequivocal in the rat. ${ }^{6)-9)}$ In the present experiments, bilateral placement of electrolytic lesions in the corticomedial portion of the amygdala, i.e., $\mathrm{ACO}, \mathrm{ABL}$, and $\mathrm{AME}$, was effective in enhancing luteinization of the ovaries in 4 of the 12 PMS-primed immature rats. These findings appear to suggest that the amygdala is involved in the hypothalamic mechanism by which PMS induces ovulation and luteinization in the animals.

Lesions placed in the corticomedial portion of the amygdala have also been shown to advance the onset of puberty in the immature female rat, ${ }^{6)}$ and to cause an increase in the synthesis and release of luteinizing hormone $(\mathrm{LH})$ in the adult female rats. ${ }^{8)}$ Similar lesions also cause luteinization in otherwise anovulatory polyfollicular ovaries of rats showing spontaneous persistent vaginal estrus. ${ }^{14)}$

These as well as the present findings seem to indicate that the amygdala or the corticomedial portion of the amygdala normally exerts an inhibitory influence upon the gonadotropic function of the hypothalamo-hypophyseal system so that the destruction of this area results in an enhanced secretion of gonadotropins, especially LH, and hence luteinization of follicles and the advancement of the onset of puberty in female rats.

On the other hand, a role of the amygdala in controlling the secretion of prolactin has also been pointed out by several workers. Implantation of a minute estrogen pellet into the amygdala evoked lactogenesis in the rabbit, ${ }^{15)}$ while destroyment of this structure caused an atrophy of rat mammary tumors, probably as a consequence of a decreased secretion of prolactin. ${ }^{16)}$ Inoué $^{1 \tau)}$ also suggested an enhanced secretion of prolactin following destruction of wide areas of the temporal lobe, including the amygdala, in male rats. However, after placement of lesions in the amygdala, PMS-primed immature rats failed to develop deciduomata in response to uterine traumatization, although the vaginal epithelium was strongly mucified in the 4 rats with heavily luteinized ovaries. It seems probable that, in these 4 animals, lesions of the amygdala resulted in an enhanced secretion of prolactin and consequently of progestins causing vaginal mucification. The failure of the uterine endometrium to form deciduomata might be accounted for by inadequate supply of progesterone 
or an inappropriate combination of progesterone and $20 \alpha$-dihydroprogesterone $(20 \alpha-\mathrm{OHP}) .^{18)}$ Yet, in view of the reports by Takewaki12),18)-21) showing that the uteri of immature rats treated with large doses of PMS and human chorionic gonadotropin (HCG) are totally unresponsive to trauma, even if placed under the influence of progesterone and estradiol in the optimal dose combination after removal of heavily luteinized ovaries, the possibility that the uteri of the 4 rats with highly stimulated ovaries were also insensitive to trauma cannot be excluded.

Summary. Bilateral electrolytic lesions were placed in the corticomedial portion of the amygdala in 23-day-old female rats of the Sprague-Dawley strain. The animals were given a subcutaneous injection of 5 I.U. PMS at 26 days of age, and endometrial trauma at 32 days. At sacrifice performed 4 days later, the ovaries of 12 rats bearing amygdaloid lesions contained a greater number of corpora lutea as compared with the 7 control rats given no brain lesions. The ovaries of 4 of the 12 lesioned rats were heavily luteinized. In the 4 animals, the vaginal epithelium was strongly mucified, although deciduomata were never formed in response to uterine trauma. These findings suggest that the amygdala, or the corticomedial portion of the amygdala, is involved in the regulation of the secretion of gonadotropins and prolactin in immature female rats.

Acknowledgement. The author wishes to express his thanks to Prof. N. Egami and Dr. S. Kawashima for their advice and encouragement, and to Professor Emeritus K. Takewaki of the University of Tokyo for his criticism and help in preparing the manuscript.

\section{References}

1) McCormack, C. E., and R. K. Meyer (1962): Proc. Soc. Exp. Biol. Med., 110, 343.

2) Zarrow, M. X., and D. L. Quinn (1963): J. Endocrinol., 26, 181.

3) Quinn, D. L., and M. X. Zarrow (1964): Endocrinology, 74, 309.

4) Coppola, J. A., R. G. Leonardi, and W. Lippmann (1966): Endocrinology, 78, 225.

5) Quinn, D. L., and M. X. Zarrow (1965): Endocrinology, 77, 255.

6) Elwers, M., and V. Critchlow (1960): Am. J. Physiol., 198, 381.

7) Velasco, M. E., and S. Taleisnik (1969): Endocrinology, 84, 132.

8) Lawton, I. E., and C. H. Sawyer (1970): Am. J. Physiol., 218, 622.

9) Arai, Y. (1971) : Endocrinol. Japon., 18, 211.

10) Machida, T., and K. Takewaki (1971): Proc. Japan Acad., 47, 81.

11) De Groot, J. (1959): Verhandl. Koninkl. Nederl. Akad. Wetensch., afd. Natuurk. ser. 2, 52(4), 1.

12) Takewaki, K. (1969): Annot. Zool. Japon., 42, 126.

13) Machida, T. (1969): Annot. Zool. Japon., 42, 68.

14) —: unpublished data. 
15) Tindal, J. S., and G. S. Knaggs (1966): J. Endocrinol., 34, ii.

16) Welsch, C. W., J. A. Clemens, and J. Meites (1969): Cancer Res., 29, 1541.

17) Inoué, S. (1969): Rep. Inst. Med. Dent. Engineer., Tokyo Med. Dent. Univ., 3, 153.

18) Takewaki, K. (1971): Proc. Japan Acad., 47, 86.

19) — (1969): Proc. Japan Acad., 45, 609.

20) - (1970): Sci. Rep. Tokyo Woman's Christian Coll., 175, no. 12-14.

21) _- (1970): Proc. Japan Acad., 46, 552. 